\title{
Perencanaan Strategis Sistem Informasi Pada Universitas XYZ Menggunakan Metode Ward and Peppard
}

\author{
Muhammad Bayu Nugraha, Gyansar Pralebda, Renny Sari Dewi \\ Fakultas Teknologi Informasi dan Kreatif, Sistem Informasi, Universitas Internasional Semen Indonesia, Gresik, Indonesia \\ Email: ${ }^{1}$ muhammad.nugraha16@student.uisi.ac.id, ${ }^{2}$ gyansar.pralebda16@student.uisi.ac.id, ${ }^{3}$ renny.dwi@uisi.ac.id
}

Submitted 23-12-2019; Accepted 10-01-2020; Published 15-02-2020

\begin{abstract}
Abstrak
Pelaksanaan dari Sistem Informasi (SI) dan Teknologi Informasi (TI) memiliki tujuan agar kinerja dari Universitas secara menyeluruh menjadi lebih efektif dan efisien. Perencanaan Strategis Sistem Informasi dilakukan supaya penerapan SI dan TI dapat memberikan hasil yang sesuai dan memenuhi target Universitas XYZ, sebuah Universitas yang membutuhkan penerapan SI/TI yang efektif agar dapat meningkatkan efisiensi dan Sumber Daya Manusia yang produktif pada Universitas XYZ secara menyeluruh. Dengan melakukan Perencanaan Strategis Sistem Informasi menggunakan metode Ward and Peppard dapat memberikan hasil dokumen Information System Strategic Planning (ISSP) yang efektif untuk membantu proses kinerja pada Universitas XYZ.
\end{abstract}

Kata Kunci: Metode Ward and Peppard, Perencanaan Strategis Sistem Informasi, Dokumen Information Strategic Planning (ISSP), Universitas XYZ, Teknologi Informasi

\begin{abstract}
The implementation of Information Systems (SI) and Information Technology (IT) has the aim that the performance of the University is fully effective and efficient. Information System Strategic Planning carried out by the implementation of SI and IT can provide results that are appropriate and meet the targets of XYZ University, a University that requires the effective application of IS / IT in order to improve efficiency and Human Resources that produce at XYZ University in full. By carrying out Information Systems Strategic Planning using Ward and Peppard methods can provide the results of an effective Strategic Information System Planning (ISSP) to assist the performance process at XYZ University.
\end{abstract}

Keywords: Ward and Peppard Method, Information Systems Strategic Planning, Information Strategic Planning (ISSP) Document, XYZ University, Information Technology

\section{PENDAHULUAN}

Merencanakan sebuah Strategi untuk sebuah Universitas merupakan bagian yang sangat penting dan harus dilakukan oleh semua universitas yang ada. Banyak Universitas yang mengalami penurunan SDM di Universitas tersebut karena tidak didukung dengan Sistem Informasi (SI) dan Teknologi Informasi (TI) yang memadai [1], [2], [3], [4].

Perencanaan Strategis SI/TI merupakan sebuah proses identifikasi identifikasi portofolio aplikasi SI yang berbasis komputer yang akan mendukung sebuah organisasi dalam pelaksanaan rencana suatu bisnis dan merealisasikan tujuan bisnisnya [5], [6], [7], [8]. Beberapa karakteristik dari perencanaan strategis SI/TI antara lain adalah adanya misi utama : Keunggulan strategis atau kompetitif dan kaitannya dengan strategi bisnis; adanya arahan dari eksekutif atau manajemen senior dan pengguna; serta pendekatan utama berupa inovasi pengguna dan kombinasi pengembangan bottom up dan analisa top down [9],[10],[4],[11].

Dalam teori Ward and Peppard perencanaan Strategis meliputi beberapa elemen. Untuk lebih jelasnya dapat dilihat pada Gambar 1.

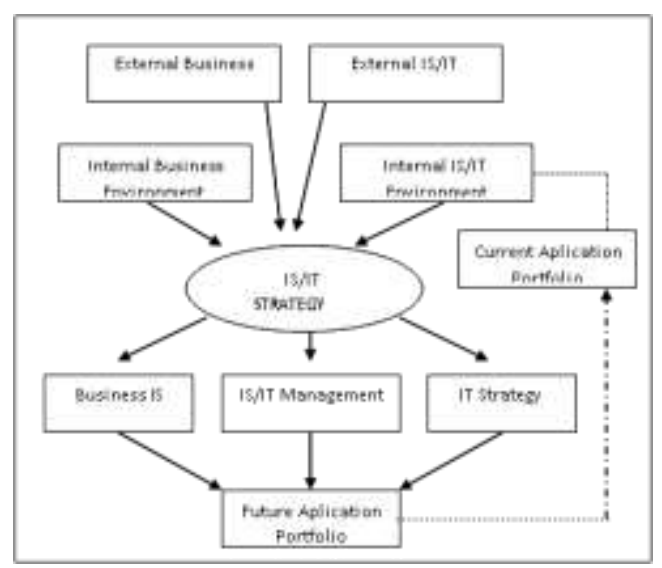

Gambar 1. menunjukkan skema perencanaan strategis SI/TI Ward dan Peppard. [5].

Agar dapat mencapai dengan apa yang sudah direncanakan dan telah diinginkan, tentunya kita harus memiliki suatu rancangan SI/TI yang efektif dan efisien. Dan dibutuhkan suatu perencanaan yang menyeluruh dan sesuai dengan spesifikasi yang dibutuhkan oleh Universitas yang akan dibangun SI/TI nya. Oleh karena itu sangat diperlukannya Perencanaan Strategis Sistem Informasi pada Universitas XYZ yang terletak di Kabupaten Gresik, Jawa Timur. Universitas XYZ memiliki misi 
untuk dapat menjadi Universitas yang dapat memanfaatkan TI secara menyeluruh dan serta mengikuti trend teknologi yang sedang berkembang saat ini. Dengan dilakukannya Perencanaan Strategis Sistem Informasi pada Universitas XYZ diharapkan dapat meningkatkan kinerja Universitas pada segmen SI/TI agar dapat berjalan secara efektif dan efisien.

\section{METODE PENELITIAN}

\subsection{Tahap Awal}

Berisi penjelasan tentang tahapan penelitian yang menggambarkan urutan logis untuk mendapatkan hasil penelitian sesuai dengan harapan dan gambaran sistem. Jika ada gambar dan tabel, itu harus disajikan dengan nama tabel dan gambar yang disertai dengan nomor urut.

\subsection{Tahap Pengumpulan Data}

Pada tahap ini dilakukan pengumpulan data terkait dilakukan dengan beberapa cara yakni dengan melakukan observasi pada Universitas XYZ, wawancara dengan berbagai narasumber, mempelajari dokumen yang ada serta melakukan studi literatur yang berkaitan dengan penelitian.

Teknik pengumpulan data [12], [2], [13], [14], [15], [16] merupakan faktor yang penting demi berhasilnya suatu penelitian, Teknik pengumpulan data dalam penelitian ini yakni:

a. Observasi

Observasi yakni dilakukan dengan melakukan pengamatan langsung pada setiap unit kerja, sistem yang digunakan dan proses bisnis di Universitas XYZ.

b. Wawancara

Wawancara dilakukan melalui tatap muka dan tanya jawab langsung antara peneliti dengan narasumber yang terkait.

c. Studi literatur

Studi literatur merupakan pengumpulan data dengan melakukan pencarian referensi teori yang relevan dengan permasalahan yang diteliti. Studi literatur dapat diperoleh melalui dokumen yang terdapat dalam organisasi, jurnal, tesis, buku, e-book dan website yang terkait dengan perencanaan strategis SI/TI.

\section{ANALISA DAN PEMBAHASAN}

Faktor penting dalam proses perencanaan strategis SI/TI adalah penggunaan hasil. Tujuan dari penggunaan hasil dalam perencanaan strategis SI adalah untuk meminimalkan risiko kegagalan, memastikan keterlibatan semua pihak yang berkepentingan serta meminimalkan ketergantungan individu, dan lebih menekankan kepada proses dan sasaran yang ditentukan.

Pendekatan hasil versi Ward and Peppard ini dimulai dari kondisi investasi SI/TI dimasa lalu yang kurang bermanfaat bagi tujuan bisnis organisasi dan menangkap peluangnya bisnis, serta fenomena meningkatkan keunggulan kompetitif suatu organisasi SI/TI bagi organisasi disebabkan karena perencanaan strategis SI/TI yang lebih fokus ke teknologi, bukan berdasarkan kebutuhan bisnis. Hasil pada versi ini terdiri dari tahapan masukan dan tahapan keluaran [5]. Tahapan masukan terdiri dari:

1. Analisis lingkungan bisnis internal, yang mencakup aspek-aspek strategi bisnis saat ini, sasaran, sumber daya, proses, serta budaya nilai-nilai bisnis pada organisasi.

2. Analisis lingkungan bisnis eksternal, yang mencakup aspek-aspek ekonomi, industry, dan iklim bersaing pada perguruan tinggi.

3. Analisis lingkungan SI/TI internal, yang mencakup kondisi SI/TI organisasi yang terdiri dari perspektif bisnis saat ini, bagaimana kematangannya (Maturity), bagaimana kontribusi terhadap bisnis, keterampilan sumber daya manusia, sumber daya dan infrastruktur teknologi, termasuk juga bagaimana portofolio dari SI/TI yang ada pada saat ini.

4. Analisis lingkungan SI/TI eksternal, yang mencakup tren teknologi dan peluang pemanfaatannya, serta penggunaan SI/TI oleh competitor, pelanggan dan pemasok.

Tabel 1. Analisis Tugas dan Fungsi Layanan IT Universitas XYZ pada Direktorat Akademik

\begin{tabular}{llll}
\hline No & Tugas & Tools & Modul \\
\hline 1 & $\begin{array}{l}\text { Memantau dan melakukan evaluasi } \\
\text { pelaksanaan kegiatan Direktorat Akademik }\end{array}$ & $\begin{array}{l}\text { Sistem Informasi Monitoring } \\
\text { Kegiatan Direktorat } \\
\text { Kemahasiswaan }\end{array}$ & $\begin{array}{l}\text { Monitoring Kegiatan } \\
\text { Direktorat Akademik }\end{array}$ \\
2 & $\begin{array}{l}\text { Menyusun laporan kegiatan Direktorat } \\
\text { Akademik secara berkala dalam rangka } \\
\text { pertanggungjawaban terhadap Wakil Rektor }\end{array}$ & $\begin{array}{l}\text { Sistem Informasi Monitoring } \\
\text { Kegiatan Direktorat }\end{array}$ & $\begin{array}{l}\text { Laporan Kegiatan } \\
\text { Akademik }\end{array}$ \\
$\begin{array}{l}\text { I Bidang Akademik dan Kemahasiswaan. } \\
\text { Kenfasilitasi mahasiswa dan dosen pengajar } \\
\text { Kalam pembelajaran secara elektronik }\end{array}$ & E-Learning & E-Learning \\
\hline
\end{tabular}


4 Memfasilitasi kebutuhan akademik maupun Perpustakaan non-akademik dalam bentuk buku

Perpustakaan Universitas XYZ

Berdasarkan pada Direktorat Akademik, terdapat ada 4 Aplikasi yang belum ada pada di Universitas XYZ.

Tabel 2. Analisis Tugas dan Fungsi Layanan IT Universitas XYZ pada Direktorat Kemahasiswaan

\begin{tabular}{llll}
\hline No & Tugas & Tools & Modul \\
\hline 1 & Mengkoordinasikan program dan kegiatan & Sistem Informasi Pengajuan & Sinkronisasi Kegiatan \\
& $\begin{array}{l}\text { peningkatan penalaran, minat, dan bakat } \\
\text { serta kesejahteraan mahasiswa yang } \\
\text { dilakukan unit-unit organisasi }\end{array}$ & Kegiatan Organisasi Mahasiswa & Organisasi Mahasiswa \\
& $\begin{array}{l}\text { kemahasiswaan } \\
\text { Melaksanakan pemberian izin atau }\end{array}$ & Sistem Informasi Pengajuan & Pengajuan Kegiatan \\
& rekomendasi kegiatan kemahasiswaan & Kegiatan Organisasi Mahasiswa & Organisasi Mahasiswa \\
\hline
\end{tabular}

Tabel 3. Analisis Tugas Dan Fungsi Layanan IT Universtias XYZ pada Direktorat Perencanaan Anggaran dan Keuangan

\begin{tabular}{llll}
\hline No & Tugas & Tools & Modul \\
\hline 1 & $\begin{array}{l}\text { Melaksanakan pengelolaan dan pemeliharaan } \\
\text { penyimpanan aset serta pendistribusian di }\end{array}$ & Sistem Informasi Pendanaan & $\begin{array}{l}\text { Pengajuan Pelaksanaan } \\
\text { Anggaran }\end{array}$ \\
& $\begin{array}{l}\text { lingkungan Universitas XYZ } \\
\text { Merencanakan dan mengevaluasi anggaran } \\
\text { dana dan keuangan Universitas XYZ }\end{array}$ & Sistem Informasi Pendanaan & $\begin{array}{l}\text { Monitoring Anggaran dan } \\
\text { Keuangan } \\
\text { Melaksanakan pemantauan dan evaluasi } \\
\text { pelaksanaan program dan anggaran serta } \\
\text { penyusunan statistika keuangan secara } \\
\text { periodik Universitas XYZ } \\
\text { Melaksanakan urusan gaji pegawai dan } \\
\text { perjalanan dinas pimpinan. }\end{array}$ \\
\end{tabular}

Analisis Tugas Dan Fungsi Layanan IT Universitas XYZ pada Direktorat Perencanaan dan pemeliharaan Sarana Prasarana.

Tabel 4. Analisis Tugas Dan Fungsi Layanan IT Universitas XYZ pada Direktorat Perencanaan dan pemeliharaan Sarana Prasarana

\begin{tabular}{llll}
\hline No & Tugas & Tools & Modul \\
\hline 1 & Mengkoordinasikan program dan kegiatan & Sistem Inventaris & Pengelolaan Aset \\
& $\begin{array}{l}\text { peningkatan penalaran, minat, dan bakat serta } \\
\text { kesejahteraan mahasiswa yang dilakukan unit- } \\
\end{array}$ & & \\
unit organisasi kemahasiswaan & & & \\
& $\begin{array}{l}\text { Mendaftar seluruh aset bergerak di lingkungan } \\
\text { kampus. }\end{array}$ & Sistem Inventaris & Daftar aset \\
& Melakukan Perencanaan, Pelaksanaan dan & Sistem Informasi Monitoring & Monitoring Sarana dan \\
& $\begin{array}{l}\text { Evaluasi Penggunaan Sarana Prasarana } \\
\text { Universitas XYZ }\end{array}$ & Sarana Prasarana & Prasarana \\
\hline
\end{tabular}

Tabel 5. Analisis Tugas Dan Fungsi Layanan IT Universitas XYZ pada Direktorat Proyek Pengembangan Kampus dan Lingkungan

\begin{tabular}{llll}
\hline No & Tugas & Tools & Modul \\
\hline 1 & Melakukan pengadaan untuk pembangunan & Sistem Informasi Master Plan & Sistem Pengambil \\
& infrastruktur Universitas XYZ dan menjamin & Pembangunan Sarana dan & Keputusan Pengadaan \\
& kualitas terhadap bahan, peralatan, dan & Prasarana Universitas XYZ & Pembangunan \\
& $\begin{array}{l}\text { bangunan agar tercapai kualitas yang } \\
\text { diinginkan. }\end{array}$ & & Insfrastruktur \\
2 & $\begin{array}{l}\text { Perencanaan pembangunan sarana dan } \\
\text { prasarana pengajaran serta pembelajaran }\end{array}$ & Sistem Informasi Master Plan & Master Plan Pembangunan \\
& $\begin{array}{l}\text { yang direncanakan secara sistematis agar } \\
\text { selaras dan sejalan dengan rencana }\end{array}$ & Prasarana Universitas XYZ & Sarana dan Prasarana \\
pengembangan kegiatan akademik dan/ & & \\
& kurikulum serta dituangkan dalam master \\
plan sarana dan prasarana. & & \\
\hline
\end{tabular}




\begin{tabular}{llll}
\hline 3 & $\begin{array}{l}\text { Melakukan analisis dampak dari } \\
\text { pembangunan infrastruktur diantaranya } \\
\text { dampak proses belajar mengajar dan dampak }\end{array}$ & Sistem Informasi Master Plan & Manajemen Risiko \\
& Prasarana Universitas XYZ & Universitas XYZ \\
& $\begin{array}{l}\text { lingkungan. } \\
\text { Melakukan pengawasan dalam pembangunan } \\
\text { infrastruktur Universitas XYZ. }\end{array}$ & $\begin{array}{l}\text { Sistem Informasi Master Plan } \\
\text { Pembangunan Sarana dan }\end{array}$ & $\begin{array}{l}\text { Monitoring Pembangunan } \\
\text { Prasarana Universitas XYZ }\end{array}$ \\
\end{tabular}

Tabel 6. Analisis Tugas Dan Fungsi Layanan IT Universitas XYZ pada Lembaga Penelitian dan Pengabdian pada Masyarakat

\begin{tabular}{llll}
\hline No & Tugas & Tools & Modul \\
\hline 1 & $\begin{array}{l}\text { Memfasilitasi sarana dan prasarana penelitian } \\
\text { yang mudah diakses dan dimanfaatkan sivitas } \\
\text { akademika dan masyarakat pengguna. }\end{array}$ & $\begin{array}{l}\text { Sistem Informasi } \\
\text { Penelitian }\end{array}$ & Kumpulan Penelitian \\
2 & $\begin{array}{l}\text { Memfasilitasi bisnis sivitas akademika dan } \\
\text { mahasiswa Universitas XYZ }\end{array}$ & Sistem Bisnis Ventura & Pengajuan Bisnis \\
\hline
\end{tabular}

Tabel 7. Analisis Tugas Dan Fungsi Layanan IT Universitas XYZ pada Direktorat Pengembangan SDMO dan Teknologi Informasi Komunikasi

\begin{tabular}{|c|c|c|c|}
\hline No & Tugas & Tools & Modul \\
\hline 1 & $\begin{array}{l}\text { Merencanakan dan melaksanakan rekrutmen, } \\
\text { promosi, mutasi, rotasi, demosi dan pemutusan } \\
\text { hubungan kerja SDM. }\end{array}$ & $\begin{array}{l}\text { Sistem Informasi } \\
\text { Pengelolaan SDM }\end{array}$ & Kumpulan Penelitian \\
\hline 2 & $\begin{array}{l}\text { Mendokumentasikan absensi dosen dan } \\
\text { karyawan. Laporan kehadiran disajikan setiap } \\
\text { bulan dengan indikator pemenuhan jumlah jam } \\
\text { wajib hadir. }\end{array}$ & $\begin{array}{l}\text { Sistem Informasi Pencatatan } \\
\text { Absensi }\end{array}$ & Pengajuan Bisnis \\
\hline 3 & $\begin{array}{l}\text { Mencatat dan mendokumentasikan seluruh } \\
\text { mahasiswa Universitas XYZ yang telah } \\
\text { melaksanakan wisuda }\end{array}$ & SIM Alumni & \\
\hline
\end{tabular}

\section{IMPLEMENTASI}

Berikut ini merupakan langkah yang dilakukan yang terdapat pada tabel 8 yang menunjukkan analisis data sebagai berikut:

Tabel 8. Analisis Data

\begin{tabular}{|c|c|c|c|}
\hline No & Data & Atribut & Analisis \\
\hline 1 & $\begin{array}{l}\text { Pantauan dan evaluasi pelaksanaan kegiatan } \\
\text { Direktorat Akademik }\end{array}$ & $\begin{array}{l}\text { Sistem Informasi Master Plan } \\
\text { Pembangunan Sarana dan } \\
\text { Prasarana Universitas XYZ }\end{array}$ & $\begin{array}{l}\text { Sistem Pengambil Keputusan } \\
\text { Pengadaan Pembangunan } \\
\text { Insfrastruktur }\end{array}$ \\
\hline 2 & Laporan Kegiatan Direktorat Akademik & $\begin{array}{l}\text { Sistem Informasi Master Plan } \\
\text { Pembangunan Sarana dan } \\
\text { Prasarana Universitas XYZ }\end{array}$ & $\begin{array}{l}\text { Master Plan Pembangunan } \\
\text { Sarana dan Prasarana } \\
\text { Universitas XYZ }\end{array}$ \\
\hline 3 & $\begin{array}{l}\text { Informasi beban kerja Dosen yang meliputi } \\
\text { Pengajaran, Penelitian, dan }\end{array}$ & $\begin{array}{l}\text { Sistem Informasi Master Plan } \\
\text { Pembangunan Sarana dan } \\
\text { Prasarana Universitas XYZ }\end{array}$ & $\begin{array}{l}\text { Manajemen Risiko } \\
\text { Pembangunan insfrastruktur } \\
\text { Universitas XYZ }\end{array}$ \\
\hline 4 & Pembelajaran secara Elektronik (E-Learning) & $\begin{array}{l}\text { Sistem Informasi Master Plan } \\
\text { Pembangunan Sarana dan } \\
\text { Prasarana Universitas XYZ }\end{array}$ & $\begin{array}{l}\text { Monitoring Pembangunan } \\
\text { Insfrastruktur Universitas } \\
\text { XYZ }\end{array}$ \\
\hline 5 & $\begin{array}{l}\text { Pemantauan dan evaluasi pelaksanaan } \\
\text { program dan anggaran serta penyusunan } \\
\text { statistika keuangan secara periodik }\end{array}$ & $\begin{array}{l}\text { Data program dan Data } \\
\text { anggaran serta penyusunan } \\
\text { statistika }\end{array}$ & Sistem Informasi Pendanaan \\
\hline 6 & $\begin{array}{l}\text { Softskill Mahasiswa melalui kegiatan } \\
\text { Kemahasiswaan (SKEM) }\end{array}$ & $\begin{array}{l}\text { Data Softskill Mahasiswa } \\
\text { (SKEM) }\end{array}$ & Sistem Informasi SKEM \\
\hline 7 & $\begin{array}{l}\text { Koordinasi program dan kegiatan } \\
\text { peningkatan penalaran, minat, dan bakat } \\
\text { serta kesejahteraan Mahasiswa yang } \\
\text { dilakukan unit-unit Organisasi } \\
\text { Kemahasiswaan }\end{array}$ & $\begin{array}{l}\text { Data Sinkronisasi Kegiatan } \\
\text { Organisasi Mahasiswa }\end{array}$ & $\begin{array}{l}\text { Sistem Informasi Pengajuan } \\
\text { Kegiatan Organisasi } \\
\text { Mahasiswa }\end{array}$ \\
\hline
\end{tabular}




\begin{tabular}{|c|c|}
\hline 8 & $\begin{array}{l}\text { Pemberian izin atau rekomendasi kegiatan } \\
\text { Kemahasiswaan }\end{array}$ \\
\hline 9 & $\begin{array}{l}\text { Pembukuan dan verifikasi pelaksanaan } \\
\text { anggaran Universitas XYZ }\end{array}$ \\
\hline 10 & $\begin{array}{l}\text { Perencanaan dan Evaluasi anggaran dana de } \\
\text { keuangan Universitas XYZ }\end{array}$ \\
\hline 11 & $\begin{array}{l}\text { Pemantauan dan evaluasi pelaksanaan } \\
\text { program dan anggaran serta penyusunan } \\
\text { statistika keuangan secara periodik } \\
\text { Universitas XYZ }\end{array}$ \\
\hline 12 & $\begin{array}{l}\text { Pelaksanaan urusan gaji pegawai dan } \\
\text { perjalanan dinas pimpinan }\end{array}$ \\
\hline 13 & $\begin{array}{l}\text { Pengelolaan dan Pemeliharaan penyimpana } \\
\text { aset serta pendistribusian di lingkungan } \\
\text { Universitas XYZ }\end{array}$ \\
\hline 14 & $\begin{array}{l}\text { Pendaftar seluruh aset yang bergerak di } \\
\text { lingkungan kampus }\end{array}$ \\
\hline 15 & $\begin{array}{l}\text { Perencanaan, Pelaksanaan dan Evaluasi } \\
\text { Penggunaan Sarana Prasarana Universitas } \\
\text { XYZ }\end{array}$ \\
\hline 16 & $\begin{array}{l}\text { Pengadaan untuk pembangunan infrastruktt } \\
\text { Akademik dan menjamin kualitas terhadap } \\
\text { bahan, perlatan, dan bangunan agar tercapa } \\
\text { kualitas yang diinginkan }\end{array}$ \\
\hline 17 & $\begin{array}{l}\text { Perencanaan pembangunan sarana dan } \\
\text { prasarana pengajaran serta pembelajaran } \\
\text { yang direncanakan secara sistematis agar } \\
\text { selaras dan sejalan dengan rencana } \\
\text { pengembangan kegiatan akademik dan/ } \\
\text { kurikulum serta dituangkan dalam master } \\
\text { plan sarana dan prasarana }\end{array}$ \\
\hline 18 & Analisa dampak dari pembangunan \\
\hline
\end{tabular}

19 Pengawasan dalam pembangunan infrastruktur Akademik

20 Fasilitator sarana dan prasarana penelitian yang dapat diakses dan dimanfaatkan civitas akademika dan masyarakat pengguna.

21 Fasilitator bisnis civitas akademika dan mahasiswa Universitas XYZ

22 Perencanaan dan pelaksanaan rekrtutmen, promosi, mutasi, rotasi, demosi dan pemutusan hubungan kerja SDM

23 Pencatatan absensi dosen dan karyawan.

24 Pencatatan dan dokumentasi seluruh Mahasiswa Universitas XYZ yang telah melaksanakan wisuda

\section{Data Pengajuan Kegiatan \\ Organisasi Mahasiswa}

Data Pengajuan Pelaksanaan

Anggaran

Data Monitoring Anggaran dan

Keuangan

Data Monitoring Anggaran dan

Keuangan

Data Penggajian dan Perjalanan

Dinas Pimpinan

Data Pengelolaan Aset

\section{Data Daftar Aset \\ Data Monitoring Sarana dan \\ Prasarana}

Data Sistem Pengambil

Keputusan Pengadaan

Pembangunan Infrastruktur

Data Master Plan Pembangunan

Sarana dan Prasarana sistem

informasi akademik

\section{Data Manajemen Risiko \\ Pembangunan Infratruktur Universitas XYZ}

Data Monitoring Pembangunan Infrastruktur Universitas XYZ

Data Kumpulan Penelitian

Data Pengajuan Bisnis

Data Pengelolaan SDM

Data Pencatatan Absensi

Data Pencatatan Alumni

Universitas XYZ
Sistem Informasi Pengajuan

Kegiatan Organisasi

Mahasiswa

Sistem Informasi Pendanaan

Sistem Informasi Pendanaan

Sistem Informasi Pendanaan

Sistem Informasi Pendanaan

Sistem Inventaris

\section{Sistem Inventaris}

Sistem Informasi Monitoring Sarana Prasarana

Sistem Informasi Master Plan Pembangunan Sarana dan Prasarana sistem informasi akademik Sistem Informasi Master Plan Pembangunan Sarana dan Prasarana sistem informai akademik

Sistem Informasi Master Plan Pembangunan Sarana dan Prasarana sistem informasi akademik Sistem Informasi Master Plan Pembangunan Sarana dan Prasarana sistem informasi akademik Sistem Informasi Penelitian

Sistem Informasi Ventura

Sistem Informasi Pengelolaan SDM

Sistem Informasi Pencatatan Absensi

Sistem Informasi Mahasiswa Alumni

Pada matriks menunjukkan tingkat biaya dan manfaat dari setiap sistem informasi.

Tabel 9. Penilaian Setiap Aplikasi

\begin{tabular}{lllll}
\hline No & Analisa Aplikasi & Kode & Biaya & Manfaat \\
\hline $\mathbf{1}$ & Sistem Informasi Monitoring Kegiatan & B1 & Sedang & Tinggi \\
& Direktorat Kemahasiswaan & & & \\
$\mathbf{2}$ & Sistem Informasi Akademik & B2 & Tinggi & Tinggi \\
$\mathbf{3}$ & E-Learning & B3 & Sedang & Tinggi \\
\hline
\end{tabular}




\begin{tabular}{|c|c|c|c|c|}
\hline 4 & Perpustakaan & B4 & sedang & sedang \\
\hline 5 & $\begin{array}{l}\text { Sistem informasi pengajuan kegiatan } \\
\text { organisasi mahasiswa }\end{array}$ & B5 & sedang & sedang \\
\hline 6 & sistem informasi pendanaan & B6 & Tinggi & Tinggi \\
\hline 7 & sistem inventaris & B7 & sedang & Tinggi \\
\hline 8 & sistem informasi monitoring & B8 & sedang & sedang \\
\hline 9 & $\begin{array}{l}\text { Sistem Informasi Master Plan } \\
\text { Pembangunan Sarana dan Prasarana sistem } \\
\text { informasi akademik }\end{array}$ & B9 & Tinggi & sedang \\
\hline 10 & Sistem Informasi Penelitian & $\mathrm{B} 10$ & sedang & Tinggi \\
\hline 11 & Sistem Bisnis Ventura & B11 & sedang & Tinggi \\
\hline 12 & Sistem Informasi Pengelolaan SDM & B12 & sedang & Tinggi \\
\hline
\end{tabular}

\begin{tabular}{lllll}
13 & Sistem Informasi Pencatatan Absensi & B13 & sedang & sedang \\
14 & SIM Alumni & B14 & sedang & sedang \\
\hline
\end{tabular}

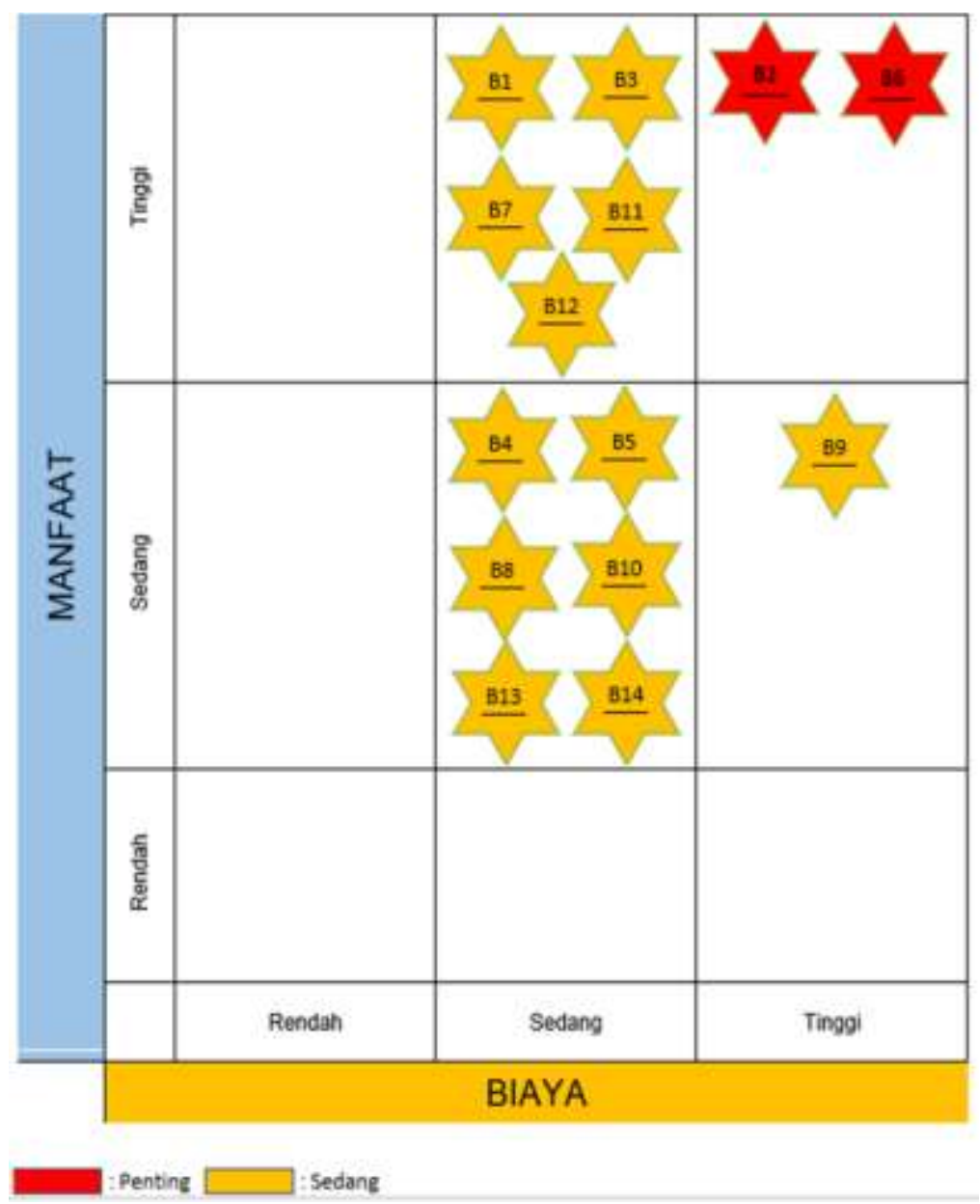

Gambar 2. Matriks Penilaian Aplikasi

Roadmap pengembangan bertujuan untuk menunjukkan pada tahun berapa sistem informasi ini akan dibuat.

Tabel 10. Roadmap Pengembangan Sistem Informasi

\begin{tabular}{llllll}
\hline \multicolumn{1}{c}{ Road Map } & 2019 & 2020 & 2021 & 2022 & 2023 \\
\hline S.I Monitoring Kegiatan & & & & & \\
Direktorat Kemahasiswaan & & & & & \\
S.I SKEM & & & & & \\
\hline
\end{tabular}




\begin{tabular}{l}
\hline S.I Pengajuan Kegiatan \\
Organisasi Mahawasiswa \\
S.I Pendanaan \\
S.I Penggajian dan perjalanan \\
dinas pimpinan \\
S.I Monitoring Sarana Prasarana \\
S.I Keputusan Pengadaan \\
pembangunan insfrastruktur \\
S.I Master Plan Pembangunan \\
Sarana dan Prasarana sistem \\
informasi akademik \\
\hline
\end{tabular}

\section{KESIMPULAN}

Berdasarkan hasil analisis yang telah dilakukan pada bab-bab sebelumnya, maka kesimpulan dari hasil analisis diantaranya adalah:

1. Metode Perencanaan Strategis Sistem Informasi menggunakan metode Ward and Peppard dapat dilakukan di Universitas XYZ dan menghasilkan dokumen ISSP.

2. Penyusunan dokumen ISSP pada Universitas XYZ sangatlah penting, karena untuk membantu proses kinerja pada Universitas XYZ.

3. Indeks Matriks Aplikasi yang terdapat pada dokumen ISSP Universitas XYZ dapat menunjukkan bahwa terdapat Penilaian Aplikasi terdapat banyak nilai sedang dan sedikitnya nilai tinggi.

4. Perencanaan Roadmap Pengembangan Sistem Informasi Universitas XYZ dilaksanakan mulai Tahun 2019 hingga tahun 2023

\section{REFERENCES}

[1] M. Afriyano, E. Darwiyanto, and A. Wisudiawan Ari, "Perencanaan Strategis Sistem Informasi Menggunakan Metode Ward and Peppard Pada PT. Grahacipta Bangko Jaya,” 2016, vol. 3, no. 2355-9365, pp. 1003-1011.

[2] D. Budiyanto and D. B. Setyohadi, "Strategic information system plan for the implementation of information technology at Polytechnic 'API' Yogyakarta," in 2017 5th International Conference on Cyber and IT Service Management, CITSM 2017, 2017.

[3] A. A. Setiyanti, D. T. Palekahelu, and E. Sediyono, "Perencanaan Pengembangan Sumber Daya Teknologi Informasi dan Komunikasi dalam Mendukung Rencana Strategis di Sekolah Menengah,” J. Buana Inform., 2016.

[4] A. Heriadi, M. Suyanto, and S. Sudarmawan, "Perencanaan Strategis Sistem Informasi STMIK Cahaya Surya Kediri," Creat. Inf. Technol. J., vol. 1, no. 1, p. 15,2015

[5] J. Ward and J. Peppard, Success Factors in Strategic Information Systems. 2002

[6] a Wedhasmara, "Langkah-Langkah Perencanaan Strategis Sistem Informasi dengan Menggunakan Metode Ward and Peppard," J. Sist. Inf., 2014.

[7] E. Susena, E. Utami, and A. Sunyoto, "Perencanaan Strategis Sistem Informasi Smart Campus Untuk Meningkatkan Pelayanan di Politeknik Indonusa Surakarta," J. Sainstech Politek. Indonusa Surakarta, 2015.

[8] J. Peppard and J. Ward, "The strategic management of information systems. Building a digital strategy.," in The strategic management of information systems: Building a digital strategy, 2016.

[9] S. Pant and C. Hsu, "Strategic Information Systems Planning: A Review," Inf. Resour. Manag. Assoc. Int. Conf., vol. 6, no. January, pp. 11-17, 1995.

[10] V. M. Kawangung, I. Wisnubhadra, and K. Anindito, "Perencanaan Strategis Sistem Informasi (Studi Kasus Di Kantor Pemberdayaan Perempuan Dan Keluarga Berencana)," Pros. Semin. NASIONALMULTI DISIPLIN ILMU\&CALL Pap. UNISBANK Kaji. Multi Disiplin Ilmu untuk Mewujudkan Poros Marit. dalam Pembang. Ekon. Berbas. Kesejaht. Rakyat, no. Snik, pp. 153-158, 2015.

[11] V. M. Kawangung, I. Wisnubhadra, and K. Anindito, "Perencanaan Strategis Sistem Informasi (Studi Kasus Di Kantor Pemberdayaan Perempuan Dan Keluarga Berencana)," Pros. Semin. NASIONALMULTI DISIPLIN ILMU\&CALL Pap. UNISBANK Kaji. Multi Disiplin Ilmu untuk Mewujudkan Poros Marit. dalam Pembang. Ekon. Berbas. Kesejaht. Rakyat, 2015.

[12] Y. Irawan, "PERENCANAAN STRATEGIS SI / TI DENGAN MENGGUNAKAN FRAMEWORK WARD AND PEPPARD DI SEKOLAH TINGGI ILMU KESEHATAN ( STIKes ),” J. Ilmu Komput., vol. 6, no. 1, pp. 25-32, 2017.

[13] Y. Firmansyah, "PERENCANAAN STRATEGIS SISTEM INFORMASI DAN TEKNOLOGI INFORMASI MENGGUNAKAN METODE WARD AND PEPPARD PADA PT AKCAYA UTAMA PRESS (PONTIANAK POST) Yoki," J. Khatulistiwa Inform., vol. vol 3, no. no 1, pp. 105-118, 2015 .

[14] A. Aziz and T. Darmizal, "Perencanaan Strategis Sistem Informasi dan Teknologi Informasi di Dinas Pendapatan, Pengelolaan Keuangan dan Aset Kabupaten Kampar (Model Strategis Ward and Peppard)," J. CoreIT J. Has. Penelit. Ilmu Komput. dan Teknol. Inf., 2016.

[15] D. Gazella, E. Darwiyanto, and G. A. A. Wisudiawan, "Perencanaan Strategis Sistem Informasi Pada Industri Manufaktur Menggunakan Metode Ward And Peppard (studi Kasus : Pt. Fin Komodo Teknologi)," eProceedings Eng., 2016.

[16] A. Mulyani, "Perencanaan Strategis Sistem Informasi Taman Satwa Menggunakan Metodologi Ward and Peppard,” J. Algoritm., vol. 14, no. 1, pp. $107-117,2017$. 